\title{
Analysis of English Idioms from Cognitive Perspective
}

\author{
Zhang Jingwei $^{1,}$, Yuan Lina ${ }^{2, b}$
}

\author{
${ }^{1}$ School of Foreign Languages, Jilin Agricultural University, Changchun,130118, China; \\ ${ }^{2}$ School of English, College of Humanities \& Sciences of Northeast Normal University, \\ Changchun, 130117, China.
}

a422820075@qq.com, b25065600@qq.com

Key Words: idiom; cognitive view; learning strategies

\begin{abstract}
Idioms are the crystallization of language, which have already attracted linguists largely, due to their particular characteristics and special functions in language. And there is a long research history of idioms. In the light of three sub-theories of cognitive linguistics namely, the theory of conceptual metaphor, the theory of conceptual metonymy and the theory of prototype categorization, this thesis attempts to analyze idioms from the perspective of cognitive linguistics. This essay aims to explore problems that we may come across in the process of idiom learning and propose some solutions and learning strategies.
\end{abstract}

\section{Introduction}

Idioms are the treasure and essence of language, cultural and historical sediment and also the indispensable existence in people's daily communication. It plays a rather important role in English. Apart from providing objective information and describing objective world, idioms can be used to express personal feelings and opinions. Idioms have been described as long words that syntactically and semantically behave as lexical entries (Titone and Connine, 1999: 1657). However, the learning of it is rather difficult, let alone the mastery. The reason is that most of English idioms are largely related to nationalities, historical development, custom, religious belief, myths and legends. An idiom is made up of several words, which has relatively fixed structure and rich meaning including both literal meaning and idiomatic meaning. According to cognitive linguistics, idioms are conceptual in nature and the meaning of them is motivated, which provide us a brand new way to look at idioms. To help non-native speakers with idiom learning, this paper tends to introduce some studies of idioms both at home and abroad. Besides, it will introduce some of the characteristics of idioms. Furthermore, it will provide a detailed analysis of idioms on the basis of three sub-theories of cognitive linguistics: the theory of prototype categorization, the theory of conceptual metaphor and the theory of conceptual metonymy as well as aims to find out some learning strategies underlying idioms for a better understanding and mastery of English idioms.

\section{Theoretical Framework}

Studies on English idioms.Hockett, a British scholar, is the representative of second-period study on idiom and has made great contribution to studies on idioms. He deems that idiom has a broad scope, including words, phrases and sentences. He proposed the following types of idioms (just some of them are introduced here)(Hockket, 1958: 73):1. Substitutes: They refer to personal pronouns like he, she and it. 2. Proper names: They include the names of people, places and new technological inventions. 3. Abbreviations: Parts of quotations may remind people of the rest of the cited piece. Like, to be or not to be is likely to remind people of the rest of Hamlet's soliloquy. 4. English Phrasal Compounds: Hockket discusses such familiar types as TheWhite House versus a white house. 5. Figures of speech: In He marries a lemon" lemon is not a kind of fruit any more but refers to "a grumpy and annoying woman”. 
The Theory of Conceptual Metaphor.Cognitive linguistics holds that metaphor is conceptual but not linguisticin nature. It no longer views metaphor as a typical character of language and a rhetorical device. It provides us a brand new perspective to comprehend metaphor. There are various definitions of conceptual metaphor. Generally, the statements include the following: metaphor is pervasive in every life, not just in our language but in thought and action. Our ordinary conceptual system, in terms of which we both think and act, is fundamentally metaphorical in nature(Lakoff and Johnson, 1980). According to Lakoff and Johnson (1980), about 70\% of expressions in English are metaphorical. Metaphor is more than a kind of expression form. As a universal cognitive model for human beings, metaphors is a process in which people understand, think and express one thing based on another. And it is conceptual in essence. In everyday life, people tend to use concepts that are familiar, structured and concrete to understand those that are unstructured, complicated and hard to definite. The former is called source domain and the latter is called the target domain.Modern cognitive linguistics holds that metaphor doesn't belong to pure language category, but the cognitive category. Conceptual metaphors are deep-seated but the formula of metaphors is superficial. So, we can see that metaphor is more a kind of cognitive category, cognitive tool or cognitive source internalized in mind than a sort of linguistic phenomenon only. From above, we know that our conceptual system is metaphorical in nature. Besides, the metaphorical conceptual system have something to do with the general social and cultural values of some ethnic group, which may explain why the same metaphorical expression generates different or even opposite interpretations in different backgrounds.

The Theory of Conceptual Metonymy.The definition of metonymy first occurred in the book RhetoricaadHerenium. Metonymy is regarded as a kind of rhetorical device, with a word substituted by a related and contiguous one. Narrowly speaking, metonymy is often defined to names of people, animals, occupations and places.

Ungerer and Schimd(2001) hold that as a kind of rhetorical device, metonymy involves close and contiguous relation between literal meaning and metaphorical meaning. Apparently, they want to emphasize the contiguity between words, which is regarded as a rather important element distinguishing metonymy from metaphor. Actually, all of the traditional views support such an opinion: metonymy is about the names of things, the name of one thing substituting the name of another. And the two things have to be related or contiguous to one another to some degree (Wang, 2011:109).

According to cognitive linguists, metonymy is conceptual in nature, just like metaphor. And some of them has become fixed (being unconscious, spontaneous and generally regarded as a kind of thinking model) and an important way to enrich language. And they call it conceptual metonymy which is considered as a kind of cognitive mechanism. "Metonymy is a cognitive process in which one conceptual entity, the vehicle, provides mental access to another conceptual entity, the target within the same domain, or we say, an idealized cognitive model (ICM)” (Kovecses, 2002:334). The cognitive meaning of metonymy differs from conventional ones. In cognitive linguistics, metonymy is a sort of linguistic phenomenon and the way how people think and act. People use the parts that are easy to understand and perceive to take the place of the whole or other parts of the whole. Suggested by the formulation of metonymy, a vehicle entity can give mental access to the target entity when they belong to the same domain.

\section{Cognitive Analysis of English Idioms}

\section{Cognitive Motivation of English Idioms}

Motivation from Metaphorical Perspective.Not only did Lakoff and Johnson (1980) argue metaphorical conceptual mappings are presented in those expressions we utilize, but also that we rely on these conceptual mappings to comprehend those expressions (Keysaret al., 2000). According to cognitive linguists, language is metaphorical in nature and metaphor is not only a linguistic phenomenon but also a thinking phenomenon. For instance, the following idioms derived from daily 
experiences: burn up(发怒), blow a fuse(大怒), kindle one's fire(怒火中烧),fly off the handle(冒 火, 激动), make one's blood boil (激怒, 使恼怒), spit the fire(愤怒至极), jump down one's throat (恼火) and so forth. From examples above, the meaning of those idioms comes from the concept "anger" but not the word. We can see that those idioms come from the metaphor "ANGER IS FIRE".

Metaphoric thought may, in many situations, have a certain role in people's understanding of at least certain types of idioms in daily communication. Both words and grammatical structures in language are linguistic units belonging to different layers and symbolic signs with internal structure, combined by both form and meaning.

Motivation from Metonymic Perspective.In the light of cognitive view, there is conceptual but not arbitrary relation between form and meaning of idiom. And correct understanding of single word in an idiom is helpful for the comprehension of the integral meaning of an idiom.

Each morpheme in idioms influences the understanding of the idioms' meaning. In the light of the theory of conceptual metonymy, motivation of idioms can be analyzed. Human organs often appear in idioms. Take "hand" as an example, it can stand for the whole concept of people, forming idioms as following: hands check on (做好准备); the action of people like hold one's hand (停止活 动); skills of people like show a mater hand (展示极强的能力, 高超的技能). There are also some other examples like nose to nose(面对面), an eye for an eye(以眼还眼, 以其人之道还治其人之 身), fresh blood(新鲜血液, 新生力量), give one's right arm(不惜血本)and so on.

The motivations can be investigated from three aspects: conceptual metaphor based on conceptual similarity, conceptual metonymy based on conceptual contiguity and encyclopedic knowledge related to experiences, which will be further talked about in the following part. In addition to conceptual metaphor and conceptual metonymy referred above, there is still encyclopedic knowledge which refers to knowledge based on experiences in one or some concepts, providing basic knowledge shared by some culture. People are able to understand relatively abstract categories by virtue of the encyclopedic knowledge.

Cognitive Mechanism of English Idioms.Cognitive mechanism of idioms refers to the process in which the meaning of an idiom is deducted through interaction between the constituents of idiom and relative factors. If we can draw an analogy like this, the process of idioms is just like raw material and the meaning of idioms is just like the product.

\section{Mechanism from Metaphorical Perspective}

The mapping of a metaphor happens in two different cognitive conceptual domains namely source domain and target domain. The metaphorical meaning of an idiom is the more generalization of its literal meaning. The metaphorical meaning (target domain) of an idiom can be seen as derived from its literal meaning (source domain). The metaphorical meaning and literal meaning of those idioms generated through metaphor are just different representations from the same cognitive path. For instance,Rob Peter to pay Paul(挖东墙补西墙), burn one's head in the sand(逃避现实), A wolf in sheep's clothing(伪君子).

From the examples above, it can be learnt that metaphorical meaning and literal meaning have common cognitive path because of the corresponding similarity between the source domain and target domain. They are the different semantic representations of the same cognitive path. There are metaphorical mapping and calque of literal meaning.

Mecahnism from Metonymic Perspective.People use metonymies for ease of cognition, expression and comprehension. Thoughts and emotions are complicated, which become entities independent on metonymic cognition related to mind. The main function of conceptual metonymy lies in that in the same cognitive model, use one category to stimulate another one so that the latter gets salience. Just like metaphor, metonymy tends to substitute abstract things by those that are concrete and contiguous. Due to the diversity of emotions, there are various phrases with "heart". There are some examples as following: steal one’s heart (偷走某人的心), asoft heart, captive one’s heart (捕获某人的心), win one's heart (赢得某人的心), lose one's heart (丧失信心), have one's heart in the right place(端正某人的态度), open one’s heart (打开某人的心扉), etc. 
In addition, Kovecses and Szabo (1996), Lakoff (1987) regards the encyclopedic knowledge as one of the cognitive mechanisms. Taking "carry coals to Newcastle" as an example, from encyclopedic knowledge we know Newcastle is the "coal city" of Britain, obviously, to where transporting coals is a waste of time and energy. So we just get the idiomatic meaning "make an unnecessary move”. And it is also a metaphorical idiom whose meaning can be motivated through encyclopedic knowledge. An idiom may have many kinds of cognitive mechanisms. Idioms are conceptual in nature. Even if concepts are structured differently, our empirical outcomes were accordant with groups of idioms with different concepts (Nayak and Gibbs, 1990).

\section{Summary}

As a part of culture, idiom is also a mirror of a nationality, reflecting its historical and cultural background, people's life style and the way people think. Idiom is powerful, with extraordinary expressive force which can make speakers express themselves clearly, precisely, colorfully. However, for non-native speakers it is a barrier in foreign language learning and its meaning is hard to understand, let alone the correct use of it. This thesis analyzed idioms from a cognitive view, presenting many features of them. From analysis above, we can see that idioms are conceptual in nature, and decomposable. As basic cognitive processes, conceptual metaphor and conceptual metonymy, provide sufficient conceptual motivations for idioms. This brand new cognitive view not only brings us new approaches to explore the origin of idioms' meaning but also gives us enlightenment. In the process of learning idioms, a large amount of semantic motivations can be found through cognitive mechanisms like conceptual metaphor and conceptual metonymy so as to deepen the understanding of the nature of idioms, improve the accuracy of use and get a better understanding of the relation between linguistic form and meaning (Zhang and Fang, 2010). The meaning of idioms is the products of conceptualization, which means people could understand idioms based on own experiences and conceptual basis but not dependent on mechanical memorizing to learn. When students learn idioms, they should not only pay attention to the motivations of idioms, but also they should take some cultural factors like geographical conditions, fables, literary art, sports and entertainment and religious belief and so on into consideration. We not only learn language, but also cultures.

\section{References}

[1] Hockett, C. F. A Course in Modern Linguistics. Language Learning, 1958, 8:73-75.

[2] Lakoff G. and Johnson, M. Metaphors We Live by. Chicago: The University of Chicago Press, 1980.

[3] Titone, D.A. and Connine, C.M. On the Compositional and NoncompositionalNature ofIdiomatic Expression. Journal of Pragmatics, 1999, 31: 1655-1674.

[4] Keysar, B., Shen, Y., Glucksberg, S. and Horton, W.S. Conventional Language: HowMetaphorical Is It . Journal of Memory and Language, 2000, 43: 576-593.

[5] Kovecses, Z. and Szabo, P. Idioms: A View from Cognitive Semantics. Applied Linguistics, 1997, 17: 326-355.

[6] Nayak, N.P. and Gibbs, R.W. Conceptual Knowledge in the Interpretation of idioms. Journal of Experimental Psychology: General, 1990, 119: 315. 